\title{
Vibration Analysis of Cracked Rotor Using Numerical Approach
}

\author{
Sri Raghava .M ${ }^{1, G}$.Diwakar ${ }^{2}$ P.Madhu Kumar ${ }^{3}$ \\ ${ }^{I}$ M.Tech Student, MechanicalEngineering Department, Prasad V Potluri Siddhartha Institute of Technology, \\ Vijayawada. \\ ${ }^{2}$ Associated professor, mechanical engineering department, Prasad V Potluri Siddhartha Institute of \\ Technology, Vijayawada. \\ ${ }^{3}$ Assistant professor, mechanical engineering department, Prasad V Potluri Siddhartha Institute of Technology, \\ Vijayawada.
}

\begin{abstract}
In general rotating machines have wide applications in systems, plants, vehicles, and industries. Every rotating machine uses shaft as power transforming unit. It is very dangerous to operate the machine with the presence of crack in the shaft. The growth of the crack is dangerous to operate and may lead to catastrophic failure. It is to be detected at earlier stages. In this paper relation between vibration amplitude and on the crack depth was developed, this helps in determine the depth of the crack by measuring the vibration amplitudes. To develop the relation equation strain energy density function was used. By observing the generated curves amplitude of vibration increases with respect to the depth of the crack due to reduction in stiffness of the shaft.
\end{abstract}

\section{Introduction:}

Fatigue cracks are trigger source of catastrophic failure in rotor shafts. Researchers have kept remarkable effort to develop a pool proof and real strategy to identify cracks in shafts. The efforts were modal the crack for reduction stiffness of shaft to estimate the response of the shaft. The equations for stiffness variation are used. Twice the running frequency component and the sub-harmonic response at approximately half the bending critical speed of the rotor have been reported to be two prominent crack indicators. The efforts were made to first modal the crack accounting for the reduction in the stiffness of the rotor segment, followed by modeling and use of stiffness variation in the equations of motion to estimate the rotor response.

Dimarogonas and papadoponlos[1] was done analysis of cracked rotor neglecting the non-liner behavior of the crack by assuming constant stiffness asymmetry and using theory of shaft with dissimilar moment of inertia ,then they derived a complete flexibility matrix of the cross-section containing the crack[2]. The flexibility matrix derived to the fully open crack. The flexibility of rotor fixed direction was considered to remain constant and the motion of cracked rotor equation were similar to an asymmetric shaft. To modal the breathing of the crack,Grabowski[5] considered switching of the stiffness values from those of an uncracked rotor (close crack state)to those of of cracked rotor (fully open state)at a particular rotor angular position (when crack edge becomes vertical ). Corresponding the switching takes place when there is a change in the sign of rotor response in rotorfixed co-ordinate in crack direction (per pendicular to crack edge).It is referred as hinge modal. Mayes and Davies[4] considered Sinusoidal stiffness variation to modal the breathing in a more sensible way as a rotor crack is expected to open and close gradually due to gravity. Then after Nelson and Nataraj[9]considered the finiteelement formulation of a crack element. They used rotating stiffness variation that depending on rotorcurvature at crack section. Schmalhorst[11] was taken constant segments on the face of crack in a finite element modal to help decide which crack face is under pressure. Prabhu[15] used finite element modal for the cracked rotor with open crack and studied fluctuation of bending stresses due to crack. Abraham and Brandom[16] proposed a substructure approach for modeling breathing behavior of crack using Lagrange multipliers.

Papdopoulos and Dimarogonas[17] proposed the issue of coupling of vibration due to crack. They proposed either of bending, longitudinal, torsional mode natural frequency, in the vibration of crack in the shaft. For this purpose they used harmonic sweeping excitation. However, this excitation is given to non-rotating shaft. Ostachowicz and Krawczuk[14] was presented by coupling of torsional and bending vibration of a rotating shaft using an open crack modal.

Collins et al and Darpe et al[22] used impulse axial excitation to a rotating cracked shaft and exploited this coupling mechanism in lateral and longitudinal direction of a cracked rotor for the purpose of diagnosis of crack.

Although a $6 \times 6$ flexibility matrix has been used in the analytical models of non-rotating shaft by previous researchers for studying coupling, finite element with all the six degrees of freedom accounting for all the coupling mechanism has not been used to explore coupling of various modes in a rotating shaft. An unrealistic model of a open crack modal and that gives different results from those obtained with a more 
appropriate breathing crack modal. Papadopoulos and Dimarogonas[19] was studied coupling between the three modes of vibration.

In this paper an attempt is made to discus some of issues mentioned above. The work presented tells the relation between lateral torsion vibrations for a rotating cracked shaft using finite element modal. The displacement matrix of the beam element is modified to account for of effort of the crack. All six types of forces are considered. This as made possible the analysis of coupling of longitudinal, bending and torsion vibration of cracked shaft. The breathing cracked modal which accounts for opening (Or) close of crack using sign of stress intensity factor at crack edge is used.

\section{Finite Element Model Of A Cracked Rotor Segment:}

Considered a rotor segment containing a single transverse surface crack. To represent this segment in the finite element modal of the cracked rotor system, the rotor segment is represented by a beam element with six degree of freedom per node. However to account for the presence of a crack, the stiffness matrix of the beam element is modified. The modified stiffness matrix takes into account all the coupling phenomena that exist in cracked rotor i.e. bending- longitudinal, bending-torsion, longitudinal-torsion. The beam element with modified stiffness matrix then fits into the complete finite element assemblage representing a rotor-bearing system and is used for further analysis.

Considered a shaft element containing a transverses surface crack of depth "a" in fig 1 small shaft segment around the crack cross-section in the rotor will be modeled as a finite beam element that will be different than the usual beam element with regard to it's stiffness properties. Let the shaft element be of diameter " $D$ " and length " $L$ ". The element is loaded with shear forces $\mathrm{q}_{2}, \mathrm{q}_{3}$, and $\mathrm{q}_{8}, \mathrm{q}_{9}$, bending moments $\mathrm{q}_{6}, \mathrm{q}_{5}$ and $\mathrm{q}_{11}, \mathrm{q}_{12}$, axial forces $\mathrm{q}_{1}, \mathrm{q}_{7}$ and torsion moments $\mathrm{q}_{4}$, and $\mathrm{q}_{10}$. Thus all the six degrees of freedom per node is considered here. The crack is situated at a distance " $\mathrm{x}$ " from the left end of the element.

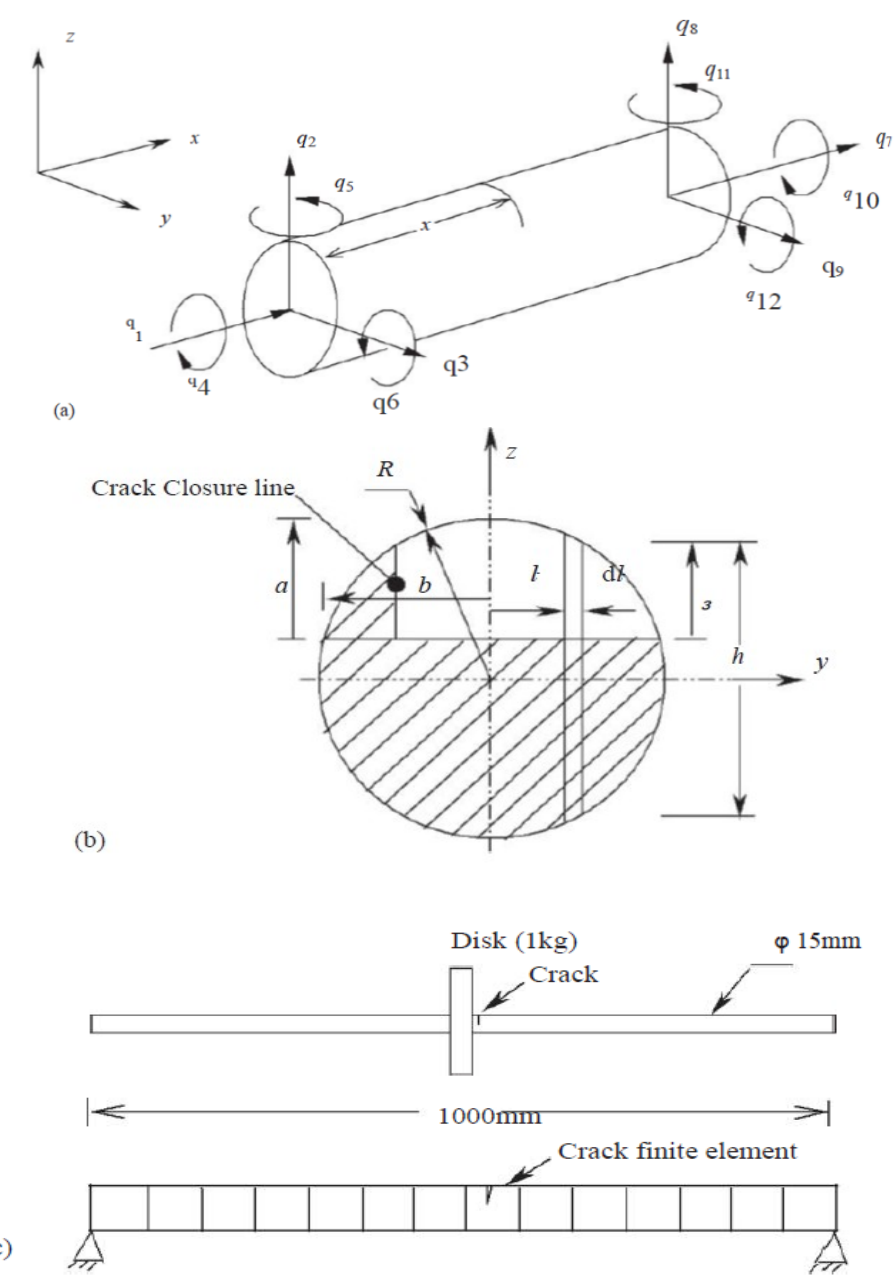

Fig1. Shaft finite element (a) The element showing force action and co-ordinate system.(b) crack crosssection.(c) a simple rotor and its finite element modal.

The flexibility matrix of the crack element is first derived. Using castingliano's theorem 


$$
\mathrm{u}_{\mathrm{i}}=\frac{\partial U}{\partial q i}
$$

Where $\mathrm{U}$ is total strain energy. That is,

$$
\mathrm{U}=\mathrm{U}^{0}+\mathrm{U}^{\mathrm{C}} \text {. }
$$

Here $\mathrm{U}^{0}$ is the strain energy of the uncracked shaft element, $\mathrm{U}^{\mathrm{c}}$ the strain energy due to crack Let $\mathrm{u}_{\mathrm{i}}$ and $\mathrm{q}_{\mathrm{i}}$ are displacement and force respectively along the $\mathrm{i}^{\text {th }}$ co-ordinate. Thus,

Which can be written as

$$
\mathrm{u}_{\mathrm{i}}=\frac{\partial U 0}{\partial q i}+\frac{\partial U c}{\partial q i}
$$

$$
\mathrm{u}_{\mathrm{i}}=\mathrm{u}_{\mathrm{i}}^{0}+\mathrm{u}_{\mathrm{i}}^{\mathrm{c}}
$$

where

$$
\mathrm{u}_{\mathrm{i}}^{0}=\frac{\partial U 0}{\partial q i}, \mathrm{u}_{\mathrm{i}}^{\mathrm{c}}=\frac{\partial U c}{\partial q i}
$$

using the strain energy approach both $\mathrm{u}_{\mathrm{i}}{ }^{0}$ and $\mathrm{u}_{\mathrm{i}}^{\mathrm{c}}$ will be derived. Considered the action of axial forces, torsion and bending moment and also accounting for shearing action at the cross-section at the cross-section of the crack the elastic strain energy of the element can written as

$U^{0}=\frac{1}{2} \int \frac{\alpha_{S} V_{1}^{2}}{G A}+\frac{\alpha_{S} V_{2}^{2}}{G A}+{\frac{M_{1}}{E I}}^{2}+\frac{M_{2}^{2}}{E I}+\frac{T^{2}}{E I_{0}}+\frac{F^{2}}{A E} d X$

Where $\mathrm{V}_{1}$ and $\mathrm{V}_{2}$ are shear forces , $\mathrm{M}_{1}, \mathrm{M}_{2}$ are bending moment , $\mathrm{T}$ is torsional moment , $\mathrm{F}$ is axial forces action at the cross-section , $\mathrm{G}$ is modulus of rigidity , $\mathrm{E}$ is young's modulus , $\mathrm{I}$ is the area moment of inertia of the crosssection, $\mathrm{I}_{0}$ is the polar moment of inertia of the cross-section and $\alpha_{s}$ is shear coefficient .

From fig 1

$\mathrm{V}_{1}=\mathrm{q}_{2}, \quad \mathrm{~V}_{2}=\mathrm{q}_{3}, \quad \mathrm{~T}=\mathrm{q}_{4}, \quad \mathrm{~F}=\mathrm{q}_{1}, \quad \mathrm{M}_{1}=\mathrm{q}_{2} \mathrm{X}-\mathrm{q}_{6} \quad$ And $\quad \mathrm{M}_{2}=\mathrm{q}_{3} \mathrm{X}+\mathrm{q}_{5}$ thus equation (5) now becomes

$U^{0}=\frac{1}{2}\left[\frac{q_{1}{ }^{2} l}{A E}+\frac{\alpha_{S q_{2}{ }^{2} l}}{G A}+\frac{q_{2}{ }^{2} l^{3}}{3 E I}+\frac{\alpha_{s} q_{3}{ }^{2} l}{G A}+\frac{q_{3}^{2} l^{3}}{3 E I}+\frac{q_{4}^{2} l}{G I_{0}}+\frac{q_{5}^{2} l}{E I}+\frac{q_{6}^{2} l}{E I}+\frac{q_{2} q_{6} l^{2}}{E I}+\frac{q_{3} q_{5} l^{2}}{E I}\right](7)$

Now individual displacements $\mathrm{u}_{\mathrm{i}}^{0}$ can be written as

$u_{1}^{0}=\frac{q_{1} l}{A E}$

$$
u_{1}^{0}=\frac{\partial U^{0}}{\partial q_{1}}=\frac{d}{d q_{1}}\left[\frac{1}{2} \frac{q_{1}^{2} l}{A E}\right]
$$

Similarly

$u_{2}^{0}=\left(\frac{\alpha_{S} l}{G A}+\frac{l^{3}}{3 E I}\right) q_{2}-\frac{l^{2}}{2 E I} q_{6}$

$$
u_{2}^{0}=\frac{\partial U^{0}}{\partial q_{2}}=\frac{d}{d q_{2}}\left[\frac{1}{2}\left(\frac{\alpha_{S} q_{2}^{2} l}{G A}+\frac{q_{2}^{2} l^{3}}{3 E I}\right)-\frac{1}{2} \frac{q_{2} q_{6} l^{2}}{E I}\right]
$$

Following similar procedure we get

$u_{3}^{0}=\left(\frac{\alpha_{S} l}{G A}+\frac{l^{3}}{3 E I}\right) q_{3}+\frac{l^{2}}{2 E I} q_{5}$,

$u_{4}^{0}=\frac{l}{G I_{0}} q_{4}$,

$u_{5}^{O}=\frac{l}{E I} q_{5}+\frac{l^{2}}{2 E I} q_{3}$,

$u_{6}^{0}=\frac{l}{E I} q_{6}-\frac{l^{2}}{2 E I} q_{2}$.

The displacement $u_{i}^{0}$ using elastic strain energy of uncracked shaft element has been obtained. Now additional displacements $u_{i}^{c}$ due to crack can be found using strain energy due to crack as follows:

$$
\mathrm{u}_{\mathrm{i}}^{\mathrm{c}}=\frac{\partial U^{c}}{\partial P_{i}}
$$

where $\mathrm{U}^{\mathrm{C}}$ Is The strain energy due to the presence of crack $\mathrm{u}_{\mathrm{i}}{ }^{\mathrm{c}}, \mathrm{q}_{\mathrm{i}}$ are additional displacements and load in direction I due to crack.

Using concepts of fracture mechanics, the additional strain energy due to crack is given by the following expression

$$
\mathrm{U}^{\mathrm{C}}=\int_{A} J(A) d A
$$

Where $\mathrm{J}(\mathrm{A})$ is strain energy density function and is expressed as 


$$
J(A)=\frac{1}{E^{\prime}}\left[\left(\sum_{i=1}^{6} K I i\right)^{2}+\left(\sum_{i=1}^{6} K I I i\right)^{2}+m\left(\sum_{i=1}^{6} K I I I i\right)^{2}\right]
$$

Here $\mathrm{E}=\mathrm{E} /(1-\vartheta)$ and $\mathrm{m}=1+\vartheta ; \vartheta$ is the poission ratio and $\mathrm{k} 1 \mathrm{i}$ is the stress intensity factors corresponding to the opening mode of crack displacement , $\mathrm{k} 2 \mathrm{i}$ is the stress intensity factor corresponding to the sliding mode of the crack displcement and and $\mathrm{k} 3 \mathrm{i}$ is the stress intensity factors corresponding to the shearing mode of crack displacement $\mathrm{i}=1-6$

These stress intensity factors (SIF) are given as follow

SIF FOR MODE I:

$$
\mathrm{KII}=\sigma_{1} \sqrt{\pi \alpha} \mathrm{F}_{1}(\alpha / h)
$$

Hence

$$
\sigma_{1=q_{1 / \pi R^{2}}}
$$

$$
\begin{aligned}
& \mathrm{K}_{\mathrm{II}}=\mathrm{q}_{1} / \pi \mathrm{R}^{2} \sqrt{\pi \propto} \mathrm{F} 1(\propto / h) \\
& \mathrm{K} 15=\sigma_{5} \sqrt{\pi \alpha} \mathrm{F}_{1}(\propto / h)
\end{aligned}
$$

And moment $\mathrm{M}_{2}=\left(\mathrm{q}_{5}+\mathrm{q}_{3} \mathrm{x}\right)$

$$
\sigma_{5=\frac{M_{2} \beta}{\left(\pi / 64 D^{4}\right)}}
$$

Hence

$$
\sigma_{6}=\frac{M_{1} \sqrt{R^{2}-\beta^{2}}}{\frac{\pi}{64 D^{4}}}
$$

$$
\begin{aligned}
\mathrm{K}_{15} & =\frac{4\left(q_{5}+q_{3} X\right) \beta}{\pi R^{4}} \sqrt{\pi \alpha} \mathrm{F}_{1}(\alpha / h) \\
\mathrm{K}_{16}=\sigma_{6} \sqrt{\pi \alpha} F_{2}\left(\frac{\alpha}{h}\right) &
\end{aligned}
$$

and moment $\mathrm{M}_{1}=\left(\mathrm{q}_{2} \mathrm{X}-\mathrm{q}_{6}\right)$,

SIF FOR MODE II;

$$
\begin{aligned}
& \mathrm{K}_{16}=\frac{2(\mathrm{q} 2 \mathrm{X}-\mathrm{q} 6) \mathrm{h}}{\pi R^{4}} \sqrt{\pi \propto} \mathrm{F}_{2}(\alpha / h) \\
& \mathrm{K}_{12}=\mathrm{K}_{13}=\mathrm{K}_{14}=0
\end{aligned}
$$

$$
\mathrm{K}_{22}=\sigma_{2} \sqrt{\pi \alpha} F I I\left(\frac{\alpha}{h}\right)
$$

Hence

$$
\sigma_{2}=\frac{K q_{2}}{\pi R^{2}}
$$

Hence

$$
\begin{aligned}
& \mathrm{K}_{22}=\frac{K q_{2}}{\pi R^{2}} \sqrt{\pi \alpha} F_{I I}\left(\frac{\alpha}{h}\right) \\
& \mathrm{K}_{24}=\sigma_{42} \sqrt{\pi \alpha} F I I\left(\frac{\alpha}{h}\right) \\
& \sigma_{42}=\frac{q_{4} \beta}{\frac{\pi}{32 D^{4}}}
\end{aligned}
$$

SIF FOR MODE III:

$$
\begin{aligned}
\mathrm{K} 24 & =\frac{2 q_{4} \beta}{\pi R^{4}} \sqrt{\pi \alpha} F I I\left(\frac{\alpha}{h}\right) \\
\mathrm{K}_{21}=\mathrm{K}_{23}=\mathrm{K}_{25}=\mathrm{K}_{26}=0 & =0
\end{aligned}
$$

Hence

$$
\begin{array}{r}
\mathrm{K}_{23}=\sigma_{3} \sqrt{\pi \alpha} F I I I\left(\frac{\alpha}{h}\right) \quad \\
\sigma_{3}=\frac{K q_{3}}{\pi R^{2}}
\end{array}
$$

$$
\begin{aligned}
\mathrm{K}_{33} & =\frac{K q_{3}}{\pi R^{2}} \sqrt{\pi \alpha} F \operatorname{III}\left(\frac{\alpha}{h}\right) \\
\mathrm{K}_{34}=\sigma_{43} \sqrt{\pi \alpha} & F I I\left(\frac{\alpha}{h}\right)
\end{aligned}
$$

$\sigma_{43}=\frac{q_{4} \sqrt{R^{2}-\beta^{2}}}{\frac{\pi}{32 D^{4}}}$

Hence

Where

$$
\begin{gathered}
\mathrm{K}_{34}=\frac{q_{4} h}{\pi R^{4}} \sqrt{\pi \alpha} F I I I\left(\frac{\alpha}{h}\right) \\
\mathrm{K}_{31}=\mathrm{K}_{32}=\mathrm{K}_{35}=\mathrm{K}_{36}=0
\end{gathered}
$$

$\mathrm{F} 1=\sqrt{\frac{2 h}{\pi \alpha} \tan \left(\frac{\pi \alpha}{2 \alpha}\right)} \frac{0.752+2.02\left(\frac{\alpha}{h}\right)+0.37\left[1-\sin \left(\frac{\pi \alpha}{2 h}\right)\right]^{3}}{\cos \left(\frac{\pi \alpha}{2 h}\right)}$ 
$\mathrm{F} 2=\sqrt{2 h / \pi \alpha \tan \left(\frac{\pi \alpha}{2 h}\right)} \frac{0.923+0.199\left[1-\sin \left(\frac{\pi \alpha}{2 h}\right)\right]^{4}}{\cos \left(\frac{\pi \alpha}{2 h}\right)}$

$\mathrm{FII}=\frac{1.222-0.561\left(\frac{\alpha}{h}\right)+0.085(\alpha / h)^{2}+0.18(\alpha / h)^{3}}{\sqrt{1-(\alpha / h)^{3}}}$

$\mathrm{FIII}=\sqrt{2 h /(\pi \alpha) \tan (\pi \alpha / 2 h)}$

Using these SIF expression in eq (15) and using J(A)in eq(14) we get

$\mathrm{U}_{1}{ }^{\mathrm{c}}=\left[\mathrm{q}_{1} I_{g 1}+\left(\mathrm{xq}_{2}-\mathrm{q}_{6}\right) I_{g 2}+\left(\mathrm{Xq}_{3}+\mathrm{q}_{5}\right) I_{g 3}\right]$

$\mathrm{u}_{2}{ }^{\mathrm{C}}=\left[X I_{g 2} \mathrm{q}_{1}+I_{g 4} \mathrm{q}_{2}+\left(\mathrm{Xq}_{2}-\mathrm{q}_{6}\right) \mathrm{XI}_{g 5}+\left(\mathrm{Xq}_{3}+\mathrm{q}_{5}\right) \mathrm{XI}_{g 6}+I_{g 7} \mathrm{q}_{4}\right.$

$\mathrm{u}_{3}{ }_{3}^{\mathrm{C}}=\left[\mathrm{XI}_{g 3} \mathrm{q}_{1}+I_{G 10} \mathrm{q}_{4}+\left(\mathrm{Xq}_{2}-\mathrm{q}_{6}\right) \mathrm{XI}_{g 6}+\left(\mathrm{Xq}_{3}+\mathrm{q}_{5}\right) \mathrm{XI}_{g 8}+I_{g 9} \mathrm{q}_{3}\right.$

$\mathrm{u}_{4}{ }^{\mathrm{C}}=\left[\mathrm{R}^{2} I_{g 7} \mathrm{q}_{2}+I_{g 10} \mathrm{q}_{3}+\left(I_{g 11}+I_{g 12}\right) q_{4}\right]$

$\mathrm{u}_{5}{ }^{\mathrm{C}}=\left[I_{g 3} \mathrm{q}_{1}+\left(\mathrm{Xq}_{2}-\mathrm{q}_{6}\right) I_{g 6}+\left(\mathrm{Xq}_{3}+\mathrm{q}_{5}\right) I_{g 8}\right]$

$\mathrm{u}_{6}{ }^{\mathrm{C}}=\left[-I_{g 2} \mathrm{q}_{1}-\left(\mathrm{Xq}_{2}-\mathrm{q}_{6}\right) I_{g 5}-\left(\mathrm{Xq}_{3}+\mathrm{q}_{5}\right) I_{g 6}\right]$

Where

$I_{g 1}=\int_{A} \frac{2 \alpha F_{1}{ }^{2}}{\pi E R^{4}} d A, I_{g 2}=\int_{A} \frac{4 h \alpha F_{1} F_{2}}{\pi E R^{6}} d A$,

$I_{g 5}=\int_{A} \frac{8 h^{2} \alpha F 2^{2}}{\pi E R^{8}} d A, I_{g 6}=\int_{A} \frac{16 h \beta \alpha F 1 F 2}{\pi E R^{8}} d A, I_{g 7}=\int_{A} \frac{4 K \alpha \beta F I I^{2}}{\pi E R^{8}} d A$,

$I_{g 8}=\int_{A} \frac{32 \beta^{2} \alpha F 1^{2}}{\pi E R^{8}} d A, I_{g 9}=\int_{A} \frac{2 m K^{2} \alpha F I I I^{2}}{\pi E R^{4}} d A, I_{g 10}=\int_{A} \frac{2 m K h \alpha F I I I^{2}}{\pi E R^{8}} d A$,

$I_{g 11}=\int_{A} \frac{8 \beta^{2} \alpha F I I^{2}}{\pi E R^{8}} d A, I g_{12}=\int_{A} \frac{2 m h^{2} \alpha F I I I^{2}}{\pi E R^{8}} d A$

Thus the total displacement $\mathrm{u}_{\mathrm{i}}$ can now be obtained by adding $\mathrm{u}_{\mathrm{i}}^{0}$ to $\mathrm{u}_{\mathrm{i}}^{\mathrm{c}}$ (eq(3)) using eq(8-13) and (25). The resulting equation can be written in matrix form as

$$
\mathrm{u}_{\mathrm{i}}=[\mathrm{G}] \mathrm{q}_{\mathrm{i}} \quad \mathrm{i}=1 \text { to6 }
$$

Here G Is A Flexibility Matrix Given By

$$
\left[\begin{array}{llllll}
g_{11} & g_{12} & g_{13} & g_{14} & g_{15} & g_{16} \\
g_{21} & g_{22} & g_{23} & g_{24} & g_{25} & g_{26} \\
g_{31} & g_{32} & g_{33} & g_{34} & g_{35} & g_{36} \\
g_{41} & g_{42} & g_{43} & g_{44} & g_{45} & g_{46} \\
g_{51} & g_{52} & g_{53} & g_{54} & g_{55} & g_{56} \\
g_{61} & g_{62} & g_{63} & g_{64} & g_{65} & g_{66}
\end{array}\right]
$$

where

$g_{11}=\frac{1}{A E}+I_{g 1}, g_{22}=\left(\frac{\alpha_{S} l}{G A}+\frac{l^{3}}{3 E I}\right)+\left(I_{g 4}+X^{2} I_{g 5}\right)$

$g_{33}=\left(\frac{\alpha_{s} l}{G A}+\frac{l^{3}}{3 E I}\right)+\left(I_{g 9}+X^{2} I_{g 8}\right), g_{44}=\frac{1}{G I_{0}}+I_{g 11}+I_{g 12}$

$g_{55}=\frac{1}{E I}+I_{g 8}, g_{66}=\frac{1}{E I}+I_{g 5}, g_{12}=g_{21}=X I_{g 2}, g_{13}=g_{31}=X I_{g 3}$,

$g_{15}=g_{51}=I_{g 3}, g_{16=} g_{61}=-I_{g 2}, g_{23}=g_{32}=x^{2} I_{g 6}$,

$g_{24}=g_{42}=R^{2} I_{g 7}, g_{34}=g_{43}=I_{g 10} \quad, g_{25}=g_{52}=x I_{g 6}, g_{35}=g_{53}=\frac{l^{2}}{2 E I}+x I_{g 8}, \quad g_{26}=g_{62}=-\frac{l^{2}}{2 E I}-x I_{g 5}$,

$g_{36}=g_{63}=-x I_{g 6}, g_{56}=g_{65}=-I_{g 6}$

We get the flexibility matrix values

If $\alpha=1$

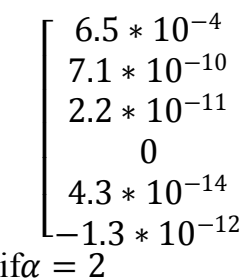

$$
\begin{array}{cc}
7.1 * 10^{-10} & 2.3 * 10^{-11} \\
0.6 & 2.6 * 10^{-15} \\
2.6 * 10^{-15} & 0.6 \\
2.8 * 10^{-15} & 1.5 * 10^{-15} \\
5.1 * 10^{-18} & 9.5 * 10^{-4} \\
-9.5 * 10^{-4} & -5.1 * 10^{-18}
\end{array}
$$$$
\begin{gathered}
0 \\
2.8 * 10^{-15} \\
1.5 * 10^{-15} \\
2.5 * 10^{-6} \\
0 \\
0
\end{gathered}
$$

$4.3 * 10^{-14}$

$5.1 * 10^{-18}$

$9.5 * 10^{-4}$

0

$1.9 * 10$

$1.9 * 10^{-6}$
$-1.5 * 10^{-15}$

$$
\left.\begin{array}{c}
-1.3 * 10^{-12} \\
-9.5 * 10^{-4} \\
-5.1 * 10^{-18} \\
0 \\
-1.5 * 10^{-15} \\
1.9 * 10^{-6}
\end{array}\right]
$$

if $\alpha=2$

If $\alpha=3$

$$
\left[\begin{array}{cccccc}
2.6 * 10^{-5} & 1.7 * 10^{-9} & 6.6 * 10^{-11} & 0 & 1.2 * 10^{-13} & -2.1 * 10^{-12} \\
1.7 * 10^{-9} & 0.6 & 6.4 * 10^{-15} & 8.1 * 10^{-14} & 1.2 * 10^{-17} & -9.5 * 10^{-4} \\
6.6 * 10^{-11} & 6.4 * 10^{-15} & 0.6 & 2.2 * 10^{-15} & 9.5 * 10^{-4} & -1.2 * 10^{-17} \\
0 & 8.1 * 10^{-14} & 2.2 * 10^{-15} & 2.4 * 10^{-6} & 0 & 0 \\
1.2 * 10^{-13} & 1.2 * 10^{-17} & 9.5 * 10^{-4} & 0 & 1.9 * 10^{-6} & -2.2 * 10^{-15} \\
-2.1 * 10^{-12} & -9.5 * 10^{-4} & -1.2 * 10^{-17} & 0 & -2.2 * 10^{-15} & 1.9 * 10^{-6}
\end{array}\right]
$$




$$
\begin{gathered}
{\left[\begin{array}{cccccc}
2.6 * 10^{-5} & 1.1 * 10^{-9} & 1.4 * 10^{-10} & 0 & 2.8 * 10^{-13} & -2.1 * 10^{-12} \\
1.1 * 10^{-9} & 0.6 & 1.2 * 10^{-14} & 1.5 * 10^{-14} & 2.3 * 10^{-17} & -9.5 * 10^{-14} \\
1.4 * 10^{-10} & 1.2 * 10^{-14} & 0.6 & 1.5 * 10^{-13} & 9.5 * 10^{-4} & -2.3 * 10^{-17} \\
0 & 1.5 * 10^{-14} & 1.5 * 10^{-13} & 2.4 * 10^{-6} & 0 & 0 \\
2.8 * 10^{-13} & 2.3 * 10^{-17} & 9.5 * 10^{-4} & 0 & 1.9 * 10^{-6} & -1.5 * 10^{-13} \\
-2.1 * 10^{-12} & -9.5 * 10^{-4} & -2.3 * 10^{-17} & 0 & -1.5 * 10^{-13} & 1.9 * 10^{-6}
\end{array}\right]} \\
{\left[\begin{array}{cccccc}
2.6 * 10^{-5} & 6.2 * 10^{-9} & 3.1 * 10^{-10} & 0 & 5.8 * 10^{-13} & -1.9 * 10^{-11} \\
6.2 * 10^{-9} & 0.6 & 2.3 * 10^{-14} & 2.5 * 10^{-14} & 4.4 * 10^{-17} & -9.5 * 10^{-14} \\
3.1 * 10^{-10} & 2.3 * 10^{-14} & 0.6 & 1.2 * 10^{-14} & 9.5 * 10^{-4} & -4.4 * 10^{-17} \\
0 & 2.5 * 10^{-14} & 1.2 * 10^{-14} & 2.4 * 10^{-6} & 0 & 0 \\
5.8 * 10^{-13} & 4 . .4 * 10^{-17} & 9.5 * 10^{-4} & 0 & 1.9 * 10^{-6} & -1.2 * 10^{-14} \\
-1.9 * 10^{-11} & -9.5 * 10^{-14} & -4.4 * 10^{-17} & 0 & -1.2 * 10^{-14} & 1.9 * 10^{-6}
\end{array}\right]}
\end{gathered}
$$

The flexibility matrix is used to fined the stiffness matrix using the transformation matrix $\mathrm{T}$ considering static equilibrium of the finite element.

$$
\{\mathrm{q} 1-12\}^{\mathrm{T}}=[\mathrm{T}]\{\mathrm{q} 1-6\}^{\mathrm{T}}
$$

Where transformation matrix given by

$$
[\mathrm{T}]^{\mathrm{T}}=\left[\begin{array}{cccccccccccc}
1 & 0 & 0 & 0 & 0 & 0 & -1 & 0 & 0 & 0 & 0 & 0 \\
0 & 1 & 0 & 0 & 0 & 0 & 0 & -1 & 0 & 0 & 0 & 1 \\
0 & 0 & 1 & 0 & 0 & 0 & 0 & 0 & -1 & 0 & -1 & 0 \\
0 & 0 & 0 & 1 & 0 & 0 & 0 & 0 & 0 & -1 & 0 & 0 \\
0 & 0 & 0 & 0 & 1 & 0 & 0 & 0 & 0 & 0 & -1 & 0 \\
0 & 0 & 0 & 0 & 0 & 1 & 0 & 0 & 0 & 0 & 0 & -1
\end{array}\right]
$$

Thus, the stiffness matrix of the crack element is written as $[k]^{c}=[T][G][T]^{T}$

\section{III.Modeling of breathing behavior of crack:}

At steady state speed far away from critical speed when the rotor is operating and without any transient excitation. The crack of breathing can be approximated either by sinusoidal stiffness variation. However, breathing behavior is represented by account gradual opening and closing of the crack using the stress intensity factor at the crack front at each instant and then finding amount of crack opening and hence the stiffness. In this process getting more accurate estimation of stiffness and more realistic representation of breathing ,this modal is suitable for all range of speeds , all types of excitation.

The integration limits for the evolution of the flexibility coefficients using eq(28) are to be taken for full width from $-b$ to $b(b$ is half-width of the crack ) and for full depth from 0 to $a$ if the crack is fully open. Papadopoulous and Dimarogonas gives local flexibility assuming the fully open crack. Using these flexibility values corresponding to fully open crack. Therefore since in practice the crack breathing, open gradually from fully closed to fully open state and there after closes gradually to fully closed state from the fully open condition. Proper integration limits need to be considered to evaluated stiffness values. This limits depend on the amount of crack opening. The fully open crack limits is taken from $-b$ to $b$, where as half open crack closed crack these limits would be either from 0 to $b$ (or) from $-b$ to o depending upon which half of the crack is open.

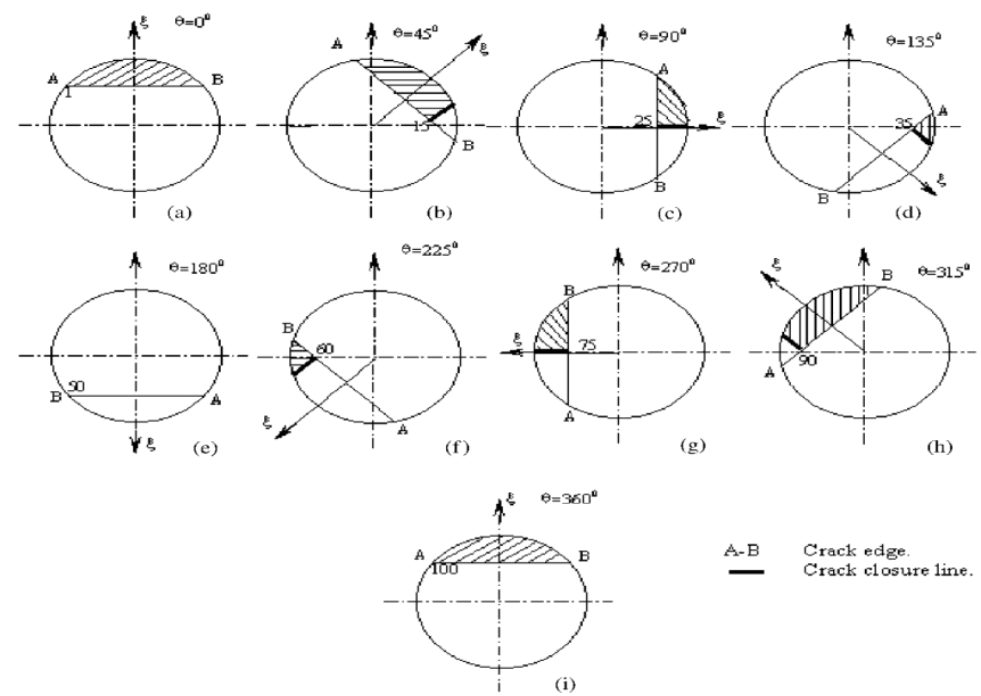

Fig2. Variation of crack closure line position with angular position of rotor 
The flexibility variation with amount of crack open, a crack closure line(CCL) is proposed. The crack closure line is an imaginary line perpendicular to the crack edge. It separates the open and close parts of the crack as shown in fig 2 as the rotor starts rotating clockwise, part of the crack near end "B" opens up. At this position the CCL has travelled from one corner B to the other corner A. When the rotor rotates further the corner B starts to partial close till the crack at $\theta=90^{\circ}$, and completely close at $\theta=360^{\circ}$. Thus the CCL position (CCLP) of 1 and 100 indicate fully closed crack state. Thus the continuous changes of CCLP is indicative of breathing of the crack.

The variation of various flexibility coefficients as a function of crack closure line position is fig 3 . The flexibility coefficients are found for a crack finite element of diameter $\mathrm{d}=15 \mathrm{mmand} \mathrm{L}=1000 \mathrm{~mm}$ , withcrackdepth $\alpha=1$ to 4 . All the direct flexibility coefficients $\left(g_{11,} g_{22,} g_{33,} g_{44,}, g_{55}\right.$ and $g_{66}$ increases to a maximum when the crack fully opens.

G11

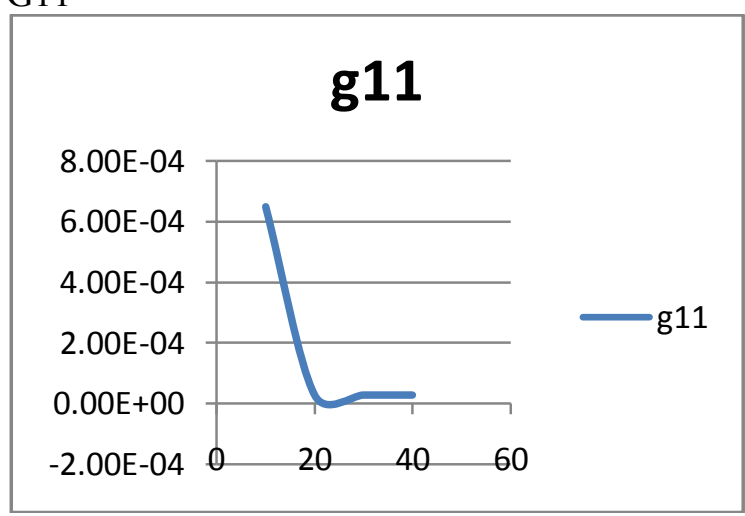

G12,G13

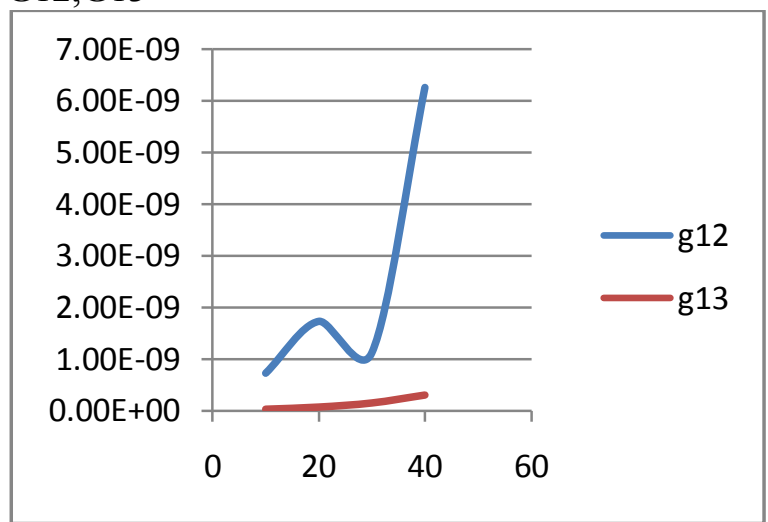

$\mathrm{G} 23, \mathrm{~g} 24, \mathrm{~g} 34$

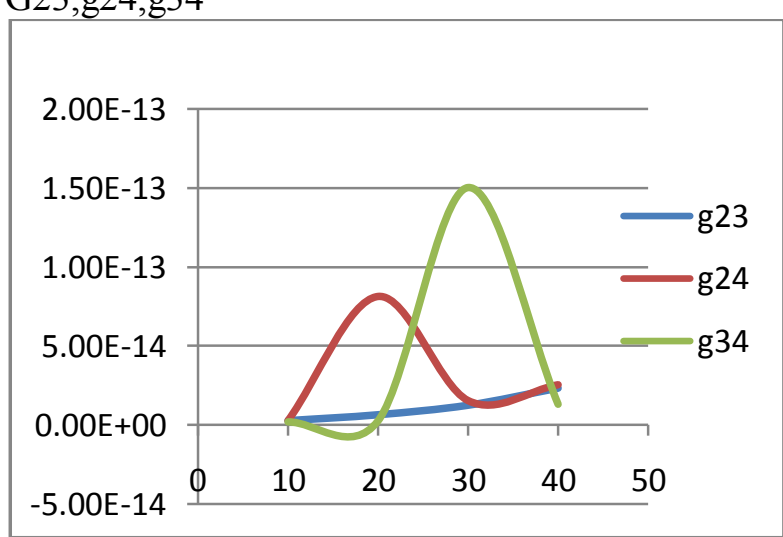

G44 ,G55,G66

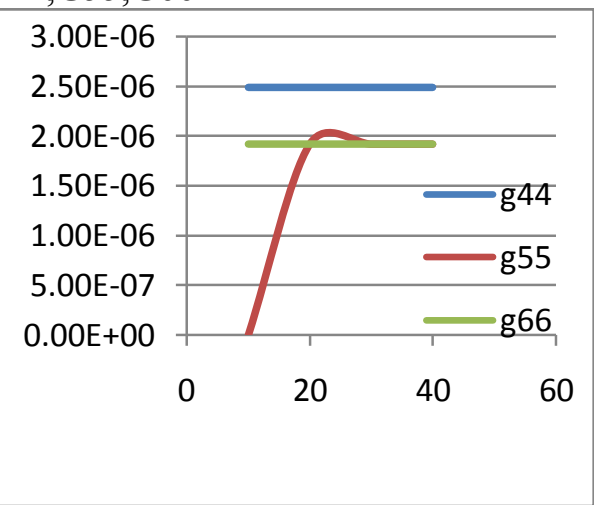

G15,g16

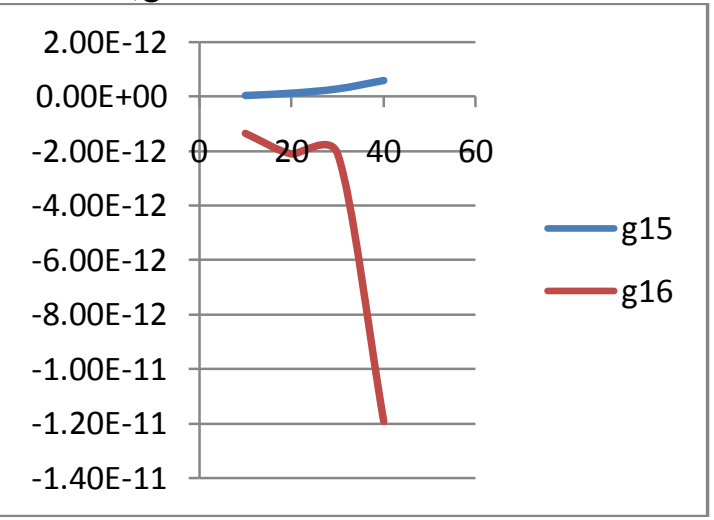

$\mathrm{G} 25, \mathrm{~g} 35, \mathrm{~g} 36$

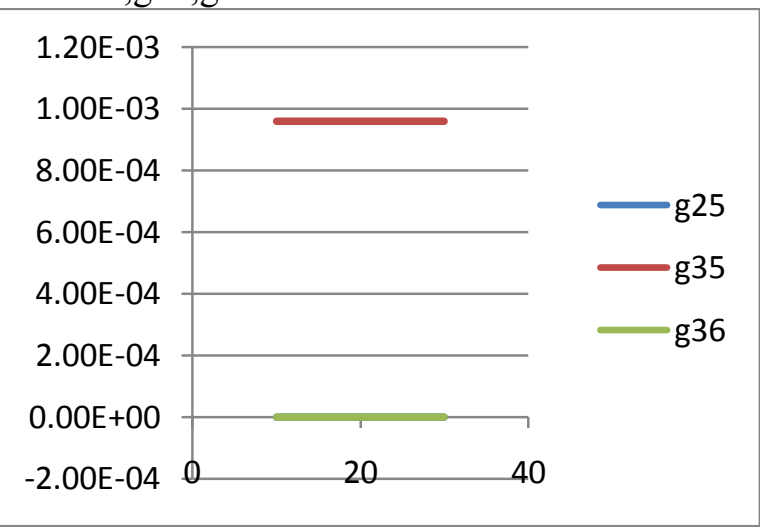

$\mathrm{X}$-axis $=$ crack closure line $\mathrm{y}$-axis $=$ flexibility $(\mathrm{rad} / \mathrm{Nmm})$ 


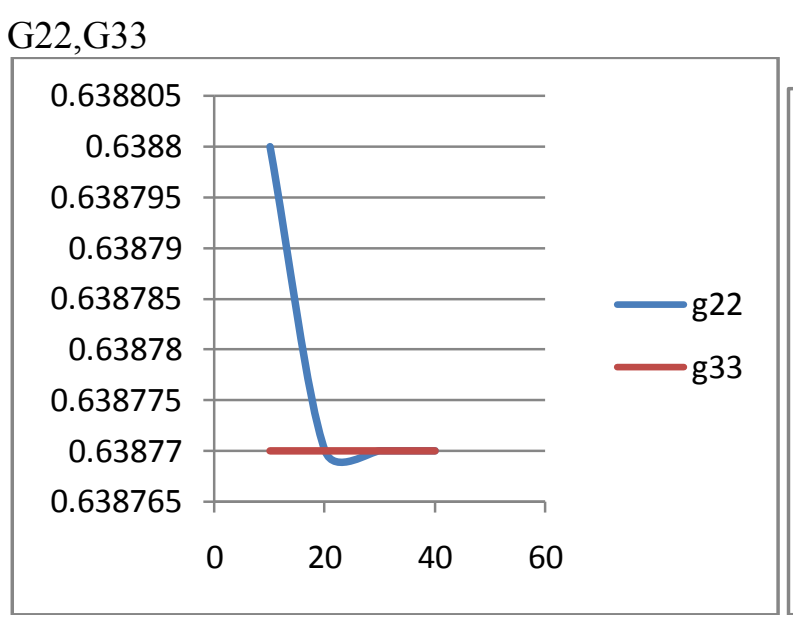

G26

\section{G56}

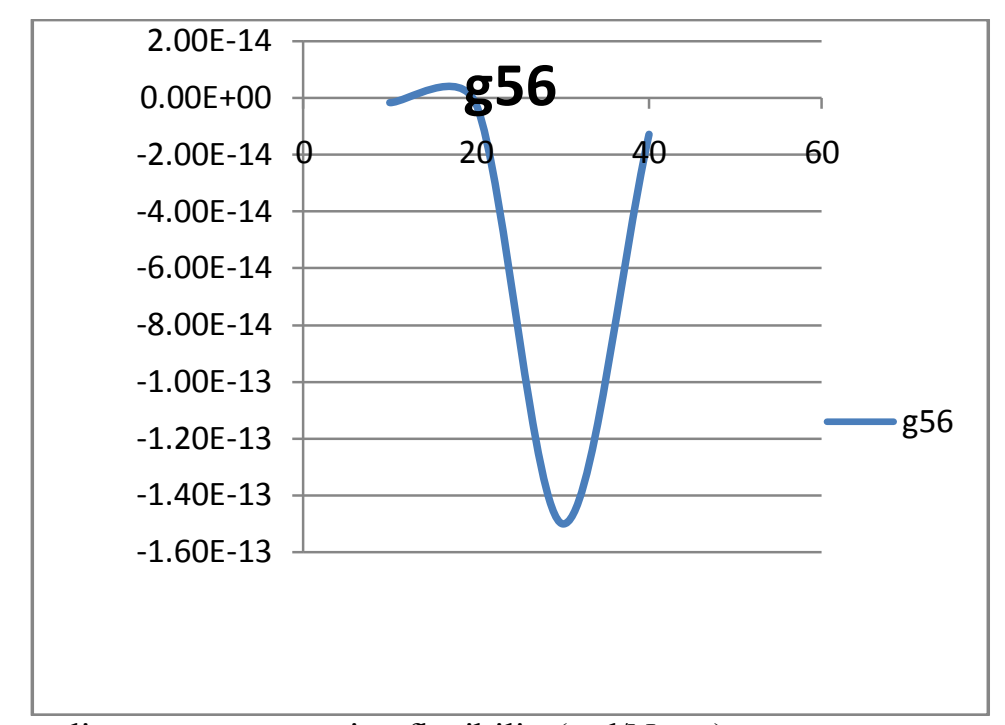

$\mathrm{X}$-axis $=$ crack closure line $\quad \mathrm{y}$-axis $=$ flexibility $(\mathrm{rad} / \mathrm{Nmm})$

Fig3. Variation of flexibility coefficients for different amount of crack opening for a crack element.

\section{Conclusion:}

Coupled longitudinal - bending - torsional vibrations have been studied using of a finite element method of cracked rotor. The displacement matrix of Timoshenko beam element with 2 degree of freedom per node is modified to account for the presence of crack this update matrix is used to representthe crack. The coupled tensional -longitudinal vibration of a rotating cracked shaft using breathing crack modal have been studied here. The crack detection based on displacement matrix could prove to be more reliable as well as convenient since displacement matrix helps to determine amplitudes of vibration of rotating shaft by measuring vibration amplitude presence of crack can be detected.

$\alpha$

\section{Appendix -Nomenclature}

$\mathrm{D}$ depth of crack

$\alpha^{\prime}$ crack depth ratio $(\alpha / \mathrm{D})$ for crack

$\mathrm{L} \quad$ length of the shaft element containing crack

$\mathrm{m} \quad$ mass of the disc

$\theta$ angle of rotation of the shaft

E Young's modulus

$q_{i}$ nodal force on the crack element

$\mathrm{u}_{\mathrm{i}}$ displacement along ith co-ordinate 


\section{References:}

[1] A.D.Dimarogona,C.A. Papadopoulos, Vibration of cracked shafts in bending, Journal of Sound and Vibration 91 (1983) $583-593$.

[2] M.D.RAJAB and A.AL SABEEH 1991 journal of Sound and vibration 147,465-473.Vibration characteristics of cracked shafts.

[3] C.A.Papadopoulos, A.D.Dimaroganas, Coupled longitudinal and bending vibrations of a rotating shaft with an open crack, Journal of a Sound and vibration 117(1987) 81-93.

[4] I.W.MAYES and W.G.DAVIES 1976 Institution of Mechanical Engineers Conference Publication ,Vibrations in Rotating Machinery ,Paper No.C168/76.The vibrational behavior of rotating shaft system containing a transverse crack.

[5] B.Grabowski , The vibration behavior of a rotating shaft containing a transverse crack, in:O.Mahenholtz(Ed.),Dynamics of Rotors-Stability and System Identification, CISM Courses and Lectures,Vol.273,Springer,Newyork,1984.

[6] R.Gasch, Dynamic behavior of a simple rotor with a cross sectional crack, in: Vibrations in Rotating Machineries-Proceedings of the International Conference ,Institution of Mechanical Engineers, 1976,pp.123-128.

[7] I.W.Mayes, W.G.R.Davies, Analysis of the response of a multi-rotor-bearing system containing a transverse crack in a rotor Journal of Vibration,Acoustics, Stress and reliability in Design 106(1984)139-145.

[8] S.Loutridis,E.Douka and A. Trochidis ,Crack identification in double-cracked beams using wavelet analysis,J.Sound vibr.277(2004), pp.1025-1039.

[9] H.D.Nelson,C.Nataraj,The dynamics of a rotor system with a cracked shaft ,Journal of Vibration ,Acoustics, Stress and Reliability in Design 108 (1986) 189-196.

[10] C.A.Papadopoulos,A.D.Dimaragonas ,Stability of cracked rotors in the coupled vibration mode,Journal of Vibration,Acoustics,Stress and Reliability in Design 110 (1988) 356-359.

[11] B.K.Schmalhorst ,Numerical simulation of cracked rotor's vibrations due to measured crack shapes, in: Proceedings of the Second International Symposium on Transport Phenomena,Dynamics and Design of Rotating Machinery,Vol 2.Honolulu,HI,1988.pp.211 225 .

[12] Li.Changhe,O.Bernasconi,N.Xenophontidis,A generalized approach to dynamics of cracked shafts,Journal of Vibration ,Acoustics, Stress and Reliability in Design 111(1989) 257-263.

[13] M.Kisa, J.Brandon and M.Topcu,Free vibration analysis of cracked beams by a combition of finite elements and component mode synthesis methods,Comput.Struct.67 (1998), pp.215-223.

[14] W.M.Ostachowicz,M.Krawczuk,Coupled torsional and bending vibrations of a rotor with an open crack,Archives of Applied Mechanics 62 (1992) 191-201.

[15] A.S.Sekhar,B.SPrabhu,Vibration and stress fluctuation in cracked shafts,Journal of Vibration of Sound and Vibration 169 (1994) $655-667$.

[16] O.N.L. Abraham,J.A.Brandon, The modeling of the opening and closure of a crack, Jouranl of Vibration and Acoustics 117(1995) $370-377$.

[17] C.A. Papadopoulos,A.D.Dimarogonas,Coupling of bending and torsional vibration of a cracked Timoshenko shaft,.IngenieurArchiv 57(1987) 257-266.

[18] C .A . Papadopoulos,A.D.Dimarogonas,Coupled longitudinal and bending vibratrion of a cracked shaft,Journal of Vibration,Acoustics,Stress and reliability in Design 110(1988) 1-8.

[19] C.A . Papadopoulos,A.D.Dimarogonas, Coupled vibration of cracked shafts, Journal of Vibration and Acoustics 114(1992) 461 467.

[20] Muszynska,P.Goldman,D.E.Benty,Torsional/lateral vibration cross-coupled responses due to shaft anisotropy: a new tool in shaft crack detection,in:Vibration in Rotating Machinery,Institution of Mechanical Engineers Conference Publications, London,1992,pp.257-262.

[21] K.R.Collians, R.H.Plaut,J.Wauer,Detection of cracks in rotating Timoshenko shafts using axial Impulses,Journal of Vibration and Acoustics 113(1991) 74-78.

[22] A.K.Darpe,A.Chawla,K.Gupta,Analysis of the response of a cracked Jeffcott rotor to axial excitation,Journal of Sound and Vibration 249 (2002) 429-445.

[23] S.Suherman,R.H.Plaut,Flexural-torsional response of a cracked rotating shaft with a disk during passage through a critical speed,in:S.C.Sinha R.M.Evan-Ianowski,(Eds.), Dynamics and vibration of Time-Varying Structures and Systems,DEVol.56,ASME,New York ,1993,pp.287-293.

[24] K.J.Bathe,Finite Element Procedures,Prentice-Hall of India, New Delhi,1996.

[25] H.D.Nelson,A finite rotating shaft element using Timoshenko b eam theory,ASME Journal of Mechanical Design 102(1980) 793803 . 